\title{
THE EVIDENCE FOR OZONE PRESERVATION IMPORTNACE IN RESTRAINING GLOBAL WARMING
}

\author{
Pavlo Lykhovyd \\ *Institute of Irrigated Agriculture of NAAS, Department of Marketing, Transfer of Innovations and Economic \\ Studies, Kherson 73483, Ukraine; \\ *Corresponding Author Pavlo Lykhovyd, e-mail: pavel.likhovid@gmail.com;
}

Received March 2021; Accepted April 2021; Published May 2021;

DOI: https://doi.org/10.31407/ijees11.305

\begin{abstract}
The challenge of global warming is one of the most important and complicated issues for modern science and technology. To efficiently restrict further aggravation of negative climate trends, scientific community must have knowledge on the key reasons for the current processes in global climatology. Most modern theories of global warming coincide in the idea that greenhouse gases, the main of which is carbon dioxide, are to blame in the gradual temperature increase. However, this theory does not embrace some other important factors, such as ozone layer depletion. The study conducted for the historical period of 1979-2020 using the data on global ozone concentration, ozone hole size, carbon dioxide concentration, and air temperature, considering the correlations between these atmospheric parameters, revealed that greenhouse gases concentration is not the only driving force of current climate change. Using the method of linear correlation analysis and Mann-Kendall and Sen's slope test it was proved that air temperature tends to increase with the increase in carbon dioxide concentration and ozone hole size, while it tends to decrease in case of ozone concentration increment and replenishment of ozone hole and ozone concentration. Therefore, ozone layer preservation is another important strategy in combating and limiting global warming.
\end{abstract}

Keywords: ozone hole, greenhouse gas, air temperature, correlation. 